\title{
PERANAN SARANA PELAYANAN KESEHATAN DALAM PEMBERIAN ASI EKSKLUSIF : STUDI PADA PEGAWAI NEGERI SIPIL DI KECAMATAN PATI
}

\author{
THE ROLE OF HEALTH CARE FACILITIES IN EXCLUSIVE \\ BREASTFEEDING : STUDY ON CIVIL SERVANTS IN PATI SUBDISTRICT
}

\author{
Aeda Ernawati \\ Kantor Penelitian dan Pengembangan Kabupaten Pati \\ Email: aeda.ernawati@yahoo.com
}

Naskah Masuk : 19 September 2014 Naskah Revisi : 2 Oktober 2014 Naskah Diterima : 16 Oktober 2014

\begin{abstract}
Regulation of Pati Regency No. 54, 2012 includes the obligation for health facilities to support the increase of breastfeeding. The purpose of this study was to illustrate the role of health facilities to support breastfeeding among mothers who work as civil servant in Pati Regency. This research used qualitative approach. Subjects were chosen using snowball sampling. Data were analyzed descriptively. The results show that some informants failed to give exclusive breastfeeding for 6 months to their child. It caused they gave infant formulas to their baby during first six months. Not all health facilities have implemented 10 steps of exclusive breastfeeding, such as: (1) socialization of the exclusive breastfeeding necessity toward pregnant mothers; (2) Guidance for delivery mother to do first breastfeeding initiative; (3) Avoidance for feeding infant, except with breastfeeding; (4) Conducting rooming in. The efforts are needed to increase exclusive breastfeeding among civil servants in Pati Regency by providing support for health facilities to run 10 steps to succesful breastfeeding and preventing infant formula promotion.
\end{abstract}

Keywords: exclusive breastfeeding, civil servants, health care facilities

\section{ABSTRAK}

Perbup Pati No. 54 Tahun 2012 berisi antara lain kewajiban instansi pelayanan kesehatan dalam upaya peningkatan pemberian ASI. Tujuan penelitian untuk menggambarkan peranan dukungan sarana pelayanan kesehatanan dalam pemberian ASI eksklusif pada ibu yang bekerja sebagai PNS Pemerintah Kabupaten Pati. Penelitian menggunakan pendekatan kualitatif. Pemilihan subjek penelitian menggunakan teknik snowball sampling. Data dianalisis secara deskriptif. Hasil penelitian menunjukkan belum semua informan berhasil memberikan ASI eksklusif pada anaknya. Penyebab kegagalan pemberian ASI eksklusif karena bayi diberi susu formula pada saat bayi baru lahir atau diberi susu formula sebelum usia 6 bulan. Belum semua sarana pelayanan kesehatan melaksanakan 10 langkah menyusui eksklusif. Diantara langkah yang belum dilakukan adalah: 1) Sosialisasi pentingnya ASI eksklusif kepada semua ibu hamil; 2) Membantu pelaksanaan inisiasi menyusui dini pada ibu yang melahirkan 3) Tidak memberikan makanan dan minuman apapun selain ASI pada bayi baru lahir; 4) Melakukan rawat gabung. Perlu upaya untuk meningkatkan pemberian ASI eksklusif di kalangan Pegawai Negeri Sipil Kabupaten Pati melalui peningkatan dukungan sarana pelayanan kesehatan dengan melaksanakan semua langkah dari 10 langkah menuju keberhasilan menyusui serta tidak mempromosikan susu formula baik secara langsung maupun tidak langsung.

Kata kunci : ASI eksklusif, pegawai negeri sipil, sarana pelayanan kesehatan 
PENDAHULUAN

Salah satu hak bayi yang dijamin oleh Undang-Undang No. 39 Tahun 2009 tentang kesehatan adalah mendapatkan Air Susu Ibu secara eksklusif (ASI eksklusif). ASI eksklusif menurut Peraturan Pemerintah Republik Indonesia No. 33 Tahun 2012 tentang Pemberian ASI Eksklusif adalah ASI yang diberikan pada bayi sejak dilahirkan selama enam (6) bulan, tanpa menambahkan dan/ mengganti dengan makanan atau minuman lain.

Pemberian ASI eksklusif pada bayi banyak memberikan manfaat bagi bayi dan ibunya (Roesli, 2005). Manfaat ASI bagi bayi antara lain sebagai makanan terbaik karena mengandung semua zat gizi yang dibutuhkan bayi, meningkatkan daya tahan tubuh, meningkatkan kecerdasan, dan meningkatkan jalinan kasih sayang antara ibu dan anak. Manfaat bagi ibu antara lain mengurangi pendarahan setelah kelahiran, mengurangi terjadinya anemia, menjarangkan kehamilan dan mengecilkan rahim. Oleh karena itu, Keputusan Kementerian Kesehatan Republik Indonesia No.1457/MENKES/SK/X/2003 tentang Standar Pelayanan Minimal (SPM) bidang Kesehatan di Kabupaten/Kota menyebutkan target cakupan pemberian ASI eksklusif minimal sebesar $80 \%$ dari bayi yang dilahirkan.

Hasil cakupan ASI eksklusif di Indonesia belum mencapi target. Berdasarkan data yang diperoleh dari profil kesehatan tahun 2012, cakupan pemberian ASI eksklusif secara nasional sebesar 48,62\%. Cakupan ASI eksklusif Provinsi Jawa Tengah tahun 2012 hanya 25,6\% (Dinkes Provinsi Jawa Tengah, 2012). Adapun cakupan pemberian ASI eksklusif di Kabupaten Pati tahun 2012 baru mencapai 62,45\% (Dinkes Kabupaten Pati, 2013).
Diantara penyebab masih rendahnya penggunaan ASI di Indonesia menurut Dirjen Gizi dan KIA Departemen Kesehatan adalah jajaran kesehatan yang belum sepenuhnya mendukung Peningkatan Pemberian ASI (PP-ASI). Masalah ini diperparah dengan gencarnya promosi susu formula dan kurangnya dukungan dari masyarakat, termasuk institusi yang memperkerjakan perempuan yang belum memberikan tempat dan kesempatan bagi ibu menyusui di tempat kerja (Depkes RI, 2011).

Upaya untuk mendorong pemberian ASI eksklusif, Pemerintah Kabupaten Pati menerbitkan Peraturan Bupati Pati No. 54 tahun 2012 tentang Peningkatan Pemberian ASI Eksklusif. Peraturan tersebut mengharuskan sarana pelayanan kesehatan mendukung keberhasilan program pemberian ASI eksklusif. Ada dua hal penting yang harus dilakukan sarana pelayanan kesehatan dalam mendukung keberhasilan program pemberian ASI eksklusif, yaitu: pertama, sarana pelayanan kesehatan harus menerapkan semua dari 10 (sepuluh) Langkah Menuju Keberhasilan Menyusui (LMKM). Kedua, sarana pelayanan kesehatan tidak memberikan dan mempromosikan susu formula pada bayi baru lahir.

Selain itu pasal 5 Peraturan Bupati Pati No. 54 Tahun 2012 menyebutkan bahwa setiap Satuan Kerja Perangkat Daerah (SKPD) harus menyediakan ruang laktasi. Adanya peraturan tersebut memberikan peluang bagi ibu yang bekerja sebagai Pegawai negeri sipil (PNS) di lingkungan Pemerintah Kabupaten Pati untuk memberikan ASI 
eksklusif kepada bayinya dengan dukungan sarana pelayanan kesehatan mengingat PNS juga mendapat jaminan kesehatan dari pemerintah selaku pemberi pekerjaan (UU RI No 24 Tahun 2011).

Widiyani (2013) menyebutkan perempuan dari kalangan pemerintah berpeluang lebih besar memberikan ASI Eksklusif kepada bayinya karena jam kerja yang fleksibel dibandingkan dengan pekerja pabrik yang mempunyai waktu istirahat terbatas yaitu hanya satu jam, padahal waktu yang digunakan untuk memerah ASI kira-kira 40 sampai 60 menit. Kondisi ini menyebabkan ibu yang bekerja sebagai PNS mempunyai kesempatan 50\% lebih besar dari ibu yang bekerja di pabrik untuk memberikan ASI pada bayinya.

Tujuan Penelitian ini untuk menggambarkan peranan dukungan sarana pelayanan kesehatan dalam pemberian ASI eksklusif pada ibu yang bekerja sebagai PNS Pemerintah Kabupaten Pati di Kota Pati.

\section{TINJAUAN PUSTAKA}

\section{Air Susu Ibu (ASI) Eksklusif}

Air Susu Ibu yang selanjutnya disingkat ASI adalah cairan hasil sekresi kelenjar payudara ibu. ASI adalah makanan terbaik untuk bayi. Tidak ada satupun makanan lain yang dapat menggantikan ASI. Untuk mendapatkan maksimal harus segera diberikan sesegera mungkin setelah dilahirkan yaitu dalam waktu 30 menit setelah lahir karena daya isap bayi saat itu paling kuat untuk merangsang produksi ASI selanjutnya (Soetjiningsih, 1997).

ASI eksklusif atau lebih tepat pemberian ASI secara eksklusif adalah bayi hanya diberi ASI saja tanpa tambahan cairan lain seperti susu formula, jeruk, madu, air teh dan air putih, serta tanpa tambahan makanan padat seperti pisang, bubur susu, biskuit, bubur nasi dan nasi tim. Pemberian ASI secara eksklusif dianjurkan selama 6 bulan sejak dilahirkan (Roesli, 2005).

Suradi dan Tobing (2004) mengemukakan dasar pemberian ASI eksklusif sampai usia enam bulan adalah : (a) ASI mengandung zat gizi yang ideal dan mencukupi untuk menjamin tumbuh kembang bayi sampai umur 6 bulan. Bayi yang mendapat makanan lain, misalnya nasi lumat atau pisang hanya akan mendapat banyak karbohidrat, sehingga zat gizi yang masuk tidak seimbang. Terlalu banyak karbohidrat menyebabkan anak lebih mudah menderita kegemukan dengan segala akibatnya; (b) bayi dibawah usia enam bulan belum mempunyai enzim pencernaan yang sempurna, sehingga belum mampu mencerna makanan dengan baik. ASI mengandung beberapa enzim yang memudahkan pencernaan makanan; (c) ginjal bayi yang masih muda belum mampu bekerja dengan baik. Makanan tambahan termasuk susu sapi biasanya mengandung banyak mineral yang dapat memberatkan fungsi ginjal yang belum sempurna pada bayi; (d) makanan tambahan mungkin mengandung zat tambahan yang berbahaya bagi bayi, misalnya zat pewarna dan zat pengawet; (e) makanan tambahan bagi bayi usia muda (kurang dari 6 bulan) mungkin menimbulkan alergi.

\section{Dukungan Sarana Pelayanan Kesehatan dalam Pemberian ASI Eksklusif}

Peraturan Bupati Pati No 54 tahun 2012 tentang Peningkatan Pemberian ASI Eksklusif mengharuskan semua sarana pelayanan kesehatan 
mendukung keberhasilan program pemberian ASI eksklusif. Bentuk dukungan berupa penerapan semua langkah dari 10 (sepuluh) Langkah Menuju Keberhasilan Menyusui (LMKM) dan tidak memberikan atau mempromosikan susu formula pada bayi baru lahir. Sarana pelayanan kesehatan menurut Peraturan Bupati Pati No. 54 Tahun 2012 adalah institusi kesehatan baik negeri maupun swasta yang memberikan pelayanan kesehatan perupa pertolongan persalinan, pemberianpengobatan, penyelenggaraan rawat inap, serta pelayanan keehatan ibu dan anak meliputi Pondok Bersalin Desa, Poliklinik Kesehatan Desa, Puskesmas Pembantu, Puskesmas, Rumah Sakit Bersalin, Balai pengobatan, Rumah Sakit, laboratorium klinik.

\section{Sepuluh Langkah Menuju}

Keberhasilan Menyusui yang tercantum dalam Peraturan Bupati Pati No. 54 Tahun 2012 pasal 4 ayat 2 yaitu :

1. Sarana pelayanan kesehatan mempunyai kebijakan Peningkatan Air Susu Ibu (PP-ASI) tertulis yang secara rutin dikomunikasikan kepada semua petugas kesehatan.

2. Melakukan pelatihan bagi petugas kesehatan dalam hal pengetahuan dan keterampilan untuk menerapkan kebijaksanaan tersebut.

3. Menjelaskan kepada semua ibu hamil tentang manfaat menyusui dan penatalaksanaannya dimulai sejak kehamilan, masa bayi lahir sampai anak umur 2 (dua) tahun termasuk cara mengatasi kesulitan menyusui.

4. Membantu ibu mulai menyusui bayinya dalam 30 menit setelah melahirkan, yang dilakukan di ruang bersalin. Apabila ibu mendapatkan operasi caesar, bayi disusui setelah 30 menit ibu sadar.

5. Membantu ibu bagaimana cara menyusui yang benar dan cara mempertahankan menyusui meski ibu dipisah dari bayi atas indikasi medis.

6. Tidak memberikan makanan atau minuman apapun selain ASI kepada bayi baru lahir.

7. Melaksanakan rawat gabung dengan mengupayakan ibu bersama bayi 24 jam sehari.

8. Membantu ibu menyusui semau bayi, tanpa pembatasan terhadap lama dan frekuensi menyusui.

9. Tidak memberikan dot atau empeng kepada bayi yang diberi ASI

10. Mengupayakan terbentuknya Kelompok Pendukung ASI (KP-ASI) dan rujuk ibu kepada kelompok tersebut ketika pulang dari rumah sakit/rumah bersalin/fasilitas pelayan kesehatan.

Adapun larangan mempromosikan susu formula baik secara langsung maupun tidak langsung diatur dalam Peraturan Bupati Pati No. 54 Tahun 2012 pasal 4 ayat 3. Sarana pelayanan kesehatan tingkat daerah dilarang mempromosikan susu formula dengan cara memasang iklan produk formula dan/atau mendisplay sampel produk susu formula, maupun secara tidak langsung dengan membekali ibu bersalin dengan produk susu formula tertentu, serta tidak menerima sponsorship dalam bentuk apapun.

\section{METODE PENELITIAN}

Jenis metode yang digunakan dalam penelitian ini adalah metode kualitatif (Idrus, 2009). Penelitian ini difokuskan pada peranan sarana pelayanan kesehatan dalam pemberian ASI eksklusif khususnya pada Pegawai Negeri Sipil (PNS). Penelitian dilaksanakan di Kabupaten Pati pada bulan Pebruari-Oktober 2014. Teknik pemilihan informan berdasarkan 
snowball sampling. Informan kunci dalam penelitian ini adalah ibu yang bekerja sebagai PNS Pemkab Pati dan mempunyai anak usia 4 sampai 11 bulan. Data penelitian mencakup data primer dan data skunder. Pengumpulan data menggunakan multiteknik meliputi : wawancara, observasi lapangan, studi dokumen. Analisis data secara deskriptif.

\section{HASIL DAN PEMBAHASAN}

\section{Karakteristik Informan}

Informan kunci dalam penelitian ini adalah ibu yang bekerja sebagai PNS Pemerintah Kabupaten Pati dan mempunyai anak usia 4 sampai 11 bulan. Karakteristik informan dapat dilihat pada Tabel 1 dan 2 .

\section{Tabel 1.}

Karakteristik Informan yang Berhasil Memberikan ASI Eksklusif

\begin{tabular}{cccccc}
\hline No. & Inisial & Umur & Pendidikan & Usia bayi & Paritas \\
\hline 1 & An & 28 & S2 & 8 & 2 \\
2 & St & 29 & S1 & 7 & 2 \\
3 & Ft & 30 & S1, sedang S2 & 7 & 1 \\
\hline
\end{tabular}

Sumber : Pengolahan Data (2014)

Tabel 2.

Karakteristik Informan yang Gagal dalam Memberikan ASI Eksklusif

\begin{tabular}{cccccc}
\hline No. & Inisial & Umur & Pendidikan & Usia bayi & Paritas \\
\hline 1 & $\mathrm{Rb}$ & 36 & $\mathrm{D} 1$ & 11 & 2 \\
2 & $\mathrm{Ks}$ & 40 & $\mathrm{~S} 1$ & 8 & 2 \\
3 & $\mathrm{El}$ & 34 & $\mathrm{~S} 1$ & 4 & 3 \\
4 & $\mathrm{Nn}$ & 28 & $\mathrm{SMA}$ & 8 & 2 \\
5 & $\mathrm{It}$ & 35 & $\mathrm{~S} 1$ & 6 & 2 \\
6 & $\mathrm{Sp}$ & 34 & $\mathrm{SMA}$ & 11 & 1 \\
7 & $\mathrm{ek}$ & 29 & $\mathrm{~S} 1$ & 7 & 1 \\
8 & $\mathrm{Mr}$ & 39 & $\mathrm{~S} 1$ & 9 & 3 \\
\hline
\end{tabular}

Sumber : Pengolahan Data (2014)

Tabel 1 menunjukkan umur informan yang memberikan ASI eksklusif semua di bawah 30 tahun. Pendidikan informan informan S1 dan S2. Informan sedang menyusui anak kesatu atau kedua. Usia bayi 7 dan 8 bulan.

Tabel 2 menunjukkan umur informan yang gagal memberikan ASI eksklusif termuda 28 tahun dan tertua 40 tahun. Pendidikan informan bervariasi, ada yang SMA, D1, S1, S2. informan sedang menyusui anak pertama, kedua atau ketiga. Usia bayi yang disusui bervariasi, usia bayi termuda usia 4 bulan dan usia bayi tertua usia 11 bulan.

\section{Praktik Pemberian ASI Eksklusif}

Berdasarkan wawancara, ada informan yang berhasil memberikan ASI eksklusif sampai 6 bulan.

"Alhamdulilah, saya bisa memberikan ASI eksklusif sampai anak usia 6 bulan. Ini saya masih lanjutkan, rencana sampai 2 tahun tanpa formula"( Informan An)

“ Syukur Alhamdulilah, dengan perjuangan akhirnya saya bisa memberikan ASI eksklusif sampai anak usia 6 bulan untuk anak kedua saya ini”'(Informan St)

"iya, Alhamdulilah, saya bisa memberikan ASI eksklusif sampai anak 
usia 6 bulan. ini masih terus saya lanjutkan. Ini masuk bulan ke delapan"(Informan $\mathrm{Ft}$ )

Beberapa informan gagal memberikan ASI eksklusif, sebagaimana diungkapkan informan $\mathrm{KS}, \mathrm{Mr}, \mathrm{Sp}, \mathrm{El}$, $\mathrm{Rb}$, Ek.

"Sejak lahir di rumah sakit langsung diberi susu formula karena ASI belum lancar"(Informan $\mathrm{Ks}, \mathrm{Mr}, \mathrm{Sp}$ )

"Diberi ASI saja hanya sampai usia 3 bulan. Setelah itu dicampur susu formula karena sudah masuk kerja dan tak sempat memerah ASI ” (Informan El)

"Sejak usia 4 bulan, saya kasih susu formula karena ASI kurang"(Informan $\mathrm{Rb)}$

"Sempat dikasih susu formula pada hari ke-2 sampai ke-4 kelahiran tetapi setelah itu ASI saja sampai usia 6 bulan"(Informan Ek)

Hasil penelitian ini menunjukkan hanya sebagian kecil informan yang berhasil memberikan ASI eksklusif pada bayinya. Masih ada informan yang tidak bisa memberikan ASI eksklusif. Berdasarkan wawancara dengan informan, penyebab gagalnya pemberian ASI eksklusif karena bayi diberi susu formula saat bayi baru lahir atau diberi susu formula sebelum bayi berusia 6 bulan.

\section{Dukungan Sarana Pelayanan Kesehatan}

Bentuk dukungan sarana pelayanan kesehatan dalam upaya peningkatan pemberian ASI Eksklusif berupa pelaksanaan semua langkah dari 10 langkah keberhasilan menyusui dan tidak mempromosikan susu formula baik secara langsung maupun tidak langsung. Berdasarkan wawancara dengan informan, belum semua sarana pelayanan kesehatan di Kabupaten Pati mendukung sepenuhnya upaya peningkatan pemberian ASI eksklusif, karena :

\section{Masih Ada Sarana Pelayanan Kesehatan yang Mempromosikan Susu Formula}

Berdasarkan wawancara dengan informan, ada informan mendapatkan susu formula yang sudah dipaketkan dengan biaya persalinan sehingga meskipun susu formula tidak diberikan pada bayi tetap harus dibayar.

"ASI belum lancar saat di Rumah Sakit. Karena sudah berniat ASI eksklusif, saya tidak memberi tambahan apa-apa. Tapi saya tetap mendapat susu formula dari RS karena sudah satu paket dengan biaya persalinan"(Informan El)

Kondisi tersebut merupakan salah satu bentuk promosi susu formula secara tidak langsung. Hal ini bertentangan dengan Peraturan Bupati Pati No. 15 tahun 2012 yang melarang sarana pelayanan kesehatan tingkat daerah mempromosikan susu formula baik secara langsung dengan memasang poster maupun secara tidak langsung dengan membekali ibu bersalin dengan produk susu tertentu.

\section{Masih Ada Sarana Pelayanan Kesehatan yang Belum Sepenuhnya Melakukan Sepuluh Langkah Menuju Keberhasilan Menyusui}

Beberapa langkah yang belum dilakukan oleh sarana pelayanan kesehatan adalah:

a) Sosialisasi Pentingnya

ASI Eksklusif kepada Semua Ibu Hamil

Berdasarkan wawancara, semua informan melakukan pemeriksaan kehamilan pada dokter Spesialis Obstretri dan Ginekologi (SpOG). Selain itu, ada beberapa informan yang 
melakukan pemeriksaan kehamilan ke bidan.

"saya periksa ke dokter spesialis kandungan rutin. Tapi.. ya... tidak pernah dapat informasi tentang ASI eksklusif”(Informan It, El, Mr)

"saya periksa ke spesialis kandungan rutin. Selain itu ke bidan juga. Saya sedikit tahu tentang ASI esksklusif ya... dari bidan. Kalo dari dokter spesialis kandungan... tidak dapat"(Informan Ft, An)

Tetapi hanya sedikit informasi tentang ASI eksklusif yang didapatkan dari petugas kesehatan. Adapun informasi yang didapat seperti batas usia bayi diberi ASI saja secara eksklusif, inisiasi menyusui dini, dan cara-cara agar ASI keluar dengan lancar. Informan tidak mendapatkan informasi cara memberikan ASI ketika ibu bekerja.

\section{b) Membantu Semua Ibu Melahirkan untuk Melakukan Inisiasi Menyusui Dini (IMD)}

Berdasarkan wawancara, ada informan yang mendapat pelayanan dari petugas kesehatan untuk melakukan IMD.

"Saya mendapat pelayanan IMD" (informan An)

"Setelah lahir, bayi saya langsung ditaruh di dada saya untuk mencari putting susu sendiri”(Informan Ks, Mr)

Tetapi, ada juga informan yang tidak mendapat pelayanan IMD, meskipun sudah meminta.

"saya tidak mendapat pelayanan IMD”(informan It, Ek)

"Saya tidak mendapat pelayanan IMD. Padahal sudah meminta" (Informan St)

IMD adalah pemberian ASI yang dilakukan seketika setelah bayi lahir dengan bayi diletakkan di dada ibu untuk mencari sendiri areola ibu. IMD merupakan faktor yang memungkinkan ibu memberikan ASI eksklusif sampai bayi berusia 6 bulan. Hasil penelitian Ida (2012) menunjukkan ibu yang melakukan IMD berpeluang 2,368 kali lebih besar memberikan ASI eksklusif sampai bayi berusia 6 bulan dibandingkan dengan ibu yang tidak melakukan IMD.

c) Tidak Memberikan Makanan dan Minuman Apapun Selain ASI pada Bayi Baru Lahir

Beberapa informan mendapatkan susu formula dari sarana pelayanan kesehatan saat melahirkan. Bayi baru lahir segera diberi susu formula oleh petugas kesehatan. Ibu bayi hanya ditanya merk susu formula untuk bayinya. Pada umumnya alasan diberikan susu formula karena ASI belum keluar pada hari pertama sampai hari ketiga melahirkan.

"saat di Rumah Sakit langsung ditanya mau pakai susu apa”(Informan Sp)

"diberi susu formula saat di RS. Langsung diberikan tanpa ditanya mau ASI eksklusif apa tidak"(Informan $\mathrm{Mr}$ )

Menurut Suradi dan Tobing (2004) banyak petugas kesehatan yang tidak tahu bahwa bayi dapat bertahan tanpa diberi makanan sampai tiga hari setelah dilahirkan. Biasanya ketika bayi sejak hari pertama dilahirkan sudah diberi susu formula, selanjutnya tetap diberi susu formula meskipun ASI sudah keluar dengan lancar dan bayi masih berusia kurang dari 6 bulan. Penelitian Kurniawan (2013) di Rumah Sakit Muhammadiyah Lamongan menunjukkan bahwa faktor pemberian susu formula selama perawatan postpartum di instansi pelayanan kesehatan menunjukkan hubungan negatif dengan keberhasilan ibu memberikan ASI eksklusif. Pemberian 
susu formula akan mempengaruhi produksi air susu ibu dan kemampuan bayi menyusu selanjutnya.

\section{d) Melakukan Rawat Gabung}

Berdasarkan wawancara dengan informan, ternyata belum semua rumah sakit memberikan pelayanan rawat gabung pada semua ibu melahirkan.

"Saya rawat gabung dengan bayi saya. Sebelumnya saya memang mencari info di beberapa rumah sakit. Dan saya memilih $R S$ yang sudah memberikan rawat gabung”(Informan $\mathrm{St}$ )

"Saya dapat rawat gabung dengan bayi saya karena saya meminta”(Informan $\mathrm{El)}$

"Tidak satu ruangan dengan bayi. Katanya yang bisa rawat gabung hanya di ruang VIP”(Informan $\mathrm{Ks}, \mathrm{Pj})$

Tidak semua informan mendapat pelayanan rawat gabung. Rawat gabung adalah salah satu cara perawatan dimana ibu dan bayi baru dilahirkan tidak dipisahkan, melainkan ditempatkan dalam sebuah ruangan selama 24 jam penuh dalam seharinya. Salah satu tujuan rawat gabung adalah agar ibu dapat menyusui bayinya sedini mungkin (Nur, 2007). Ada rumah sakit yang menyediakan perawatan rawat gabung hanya di ruang VIP. Selain itu, ada informan yang mendapat rawat gabung karena permintaan informan.

Hasil penelitian menunjukkan informan yang berhasil memberikan ASI eksklusif sampai bayi berusia 6 bulan mendapatkan dukungan dari sarana pelayanan kesehatan yang lebih memadai dibandingkan ibu yang gagal memberikan ASI eksklusif. Bentuk dukungan berupa pelayanan IMD, rawat gabung dan tidak memberikan makanan dan minuman selain ASI pada bayi baru lahir.

RSUD SAA Soewondo dan RS. Keluarga Sehat Hospital (KSH) merupakan rumah sakit di Kabupaten Pati yang banyak menjadi pilihan masyarakat di Kabupaten Pati. Informasi dari RSUD SAA Soewondo menyatakan bahwa rumah sakit sudah menerapkan 10 langkah menuju keberhasilan menyusui. Ketika masih ada ibu menyusui belum mendapat pelayanan salah satu langkah dari 10 langkah menuju keberhasilan menyusui maka pengawasan yang perlu ditingkatkan. Sedangkan dari RS. KSH menyatakan setelah ada pegawai yang mengikuti pelatihan konselor ASI yang diadakan oleh Dinas Kesehatan Kabupaten Pati pada pertengahan tahun 2014, beberapa langkah dari 10 keberhasilan menyusui dapat diterapkan seperti tidak memberikan makanan pada bayi baru lahir sampai 2 x 24 jam.

\section{KESIMPULAN DAN SARAN}

\section{Kesimpulan}

Belum semua informan berhasil memberikan ASI eksklusif pada anaknya. Penyebab kegagalan pemberian ASI eksklusif karena bayi diberi susu formula pada saat bayi baru lahir atau diberi susu formula sebelum usia 6 bulan. Belum semua sarana pelayanan kesehatan melaksanakan 10 langkah menyusui eksklusif. Diantara langkah yang belum dilakukan adalah: 1) sosialisasi pentingnya ASI eksklusif kepada semua ibu hamil; 2) membantu semua ibu melahirkan untuk melakukan Inisiasi Menyusui Dini (IMD); 3) petugas kesehatan tidak memberikan makanan dan minuman apapun selain ASI pada bayi baru lahir; 4) melakukan rawat gabung. Dukungan yang memadai dari sarana pelayanan kesehatan menunjang keberhasilan pemberian ASI eksklusif.

\section{Saran}

Perlu upaya untuk meningkatkan pemberian ASI eksklusif khususnya di 
kalangan PNS Kabupaten Pati melalui peningkatan dukungan sarana pelayanan kesehatan dengan tidak mempromosikan susu formula baik secara langsung maupun tidak langsung dan melaksanakan semua langkah dari 10 langkah keberhasilan menyusui terutama; 1). sosialisasi kepada semua ibu hamil tentang manfaat menyusui dan penatalaksanaannya dimulai sejak kehamilan, masa bayi lahir sampai anak umur 2 (dua) tahun termasuk cara mengatasi kesulitan menyusui; 2). membantu semua ibu melahirkan untuk melakukan Inisiasi Menyusui Dini (IMD); 3) petugas kesehatan tidak memberikan makanan dan minuman apapun selain ASI pada bayi baru lahir; 4) melaksanakan rawat gabung dengan mengupayakan ibu bersama bayi 24 jam sehari.

\section{DAFTAR PUSTAKA}

Dinas Kesehatan Kabupaten Pati. 2013. Profil Kesehatan Kabupaten Pati Tahun 2012. Pati.

Dinas Kesehatan Provinsi Jawa Tengah. 2013. Profil Kesehatan Provinsi Jawa Tengah Tahun 2012. Semarang.

Departemen Kesehatan Republik Indonesia. 2011 . Banyak sekali manfaat ASI bagi Bayi dan Ibu melalui.

http://www.bppsdmk.depkes.go.id/i ndex.php?option=com_content $\& v i$ ew $=$ article $\& i d=170:$ banyak sekali-manfaat-asi-bagi-bayi-dan$i b u \&$ catid $=38$ : berita \&Itemid $=82$, diakses tanggal 18 januari 2013.

Ida, 2012. Faktor-faktor yang berhubungan dengan Pemberian ASI Eksklusif 6 Bulan di Wilayah Kerja Puskesmas Kemiri Muka Kota Depok Tahun 2011. Tesis.
Magister Kesehatan Masyarakat. Jakarta : Universitas Indonesia.

Idrus, M. 2009. Metode Penelitian Sosial Pendekatan Kualitatif dan Kuantitatif. Jakarta : Erlangga.

Kementerian Kesehatan Republik Indonesia. 2013. Profil Kesehatan Indonesia Tahun 2012. Jakarta.

Keputusan Menteri Kesehatan Republik Indonesia Nomor 1457/Menkes/SK/X/2003 tentang Standar Pelayanan Minimal Bidang Kesehatan di Kabupaten Kota.

Kurniawan, B. 2013. Determinan Keberhasilan Pemberian Air Susu Ibu Eksklusif. Jurnal Kedokteran Brawijaya, Vol. 27(4) : 236-240.

Nur, D. A. 2007. Faktor yang berperan dalam kegagalan Praktik Pemberian ASI eksklusif (Studi Kualitatif di Kecamatan Tembalang, Kota Semarang Tahun 2007). Tesis. Magister Gizi Masyarakat. Semarang : Universitas Diponegoro.

Peraturan Bupati Pati Nomor 54 Tahun 2012 tentang Peningkatan Pemberian Air Susu Ibu.

Peraturan Menteri Kesehatan Republik Indonesia Nomor 15 Tahun 2013 tentang Fasilitas khusus untuk Menyusui dan Memerah ASI.

Peraturan Pemerintah Republik Indonesia Nomor 33 Tahun 2012 tentang Pemberian ASI Eksklusif.

Roesli, U. 2005. Mengenal ASI Eksklusif. Jakarta : Trubus Agriwidya.

Soetjiningsih. 2007. Seri Gizi Klinik, ASI Petunjuk untuk Tenaga Kesehatan. Jakarta : Penebit Buku Kedokteran EGC.

Suradi, R dan H. K. P. Tobing. 2004. Manajemen Laktasi Cetakan 2. 
Jakarta : Program Manajemen Laktasi Perkumpulan Perinatologi Indonesia.

Undang-Undang Republik Indonesia Nomor 24 Tahun 2011 tentang Badan Penyelenggara Jaminan Sosial.

Undang-Undang Republik Indonesia Nomor 39 Tahun 2009 tentang Kesehatan.

Widiyani, R. 2013. PNS Lebih Berpeluang Beri ASI Eksklusif. http://health.kompas.com/read/201 3/05/15/09033841/PNS.Lebih.Ber peluang.Beri.ASI. Eksklusif, diakses 18 November 2013.

\section{BIODATA PENULIS}

Aeda Ernawati, lahir 22 November 1976 di kota Purworejo Jawa Tengah. Magister Gizi Masyarakat Universitas Diponegoro Semarang. Bekerja sebagai peneliti di Kantor Penelitian dan Pengembangan Kabupaten Pati. 